\title{
DEVELOPMENT OF MATHEMATICAL MODEL OF CONCEPT OF SUBJECTIVE EMOTIONAL ASPECT OF VALUATION
}

\author{
Georgs Mote*, Janis Vanags, Ineta Geipele \\ Riga Technical University \\ Riga, Latvia \\ E-mail: seav.concept@,gmail.com \\ James Bowen \\ University of Ottawa \\ Ottawa, Canada
}

\begin{abstract}
Some time ago, one of authors was told by an experienced marketing practitioner the difference between a successful sales manager and one who is not successful. He assumed the successful sales manager is one who is the cleverest, works the hardest and knows the most. But, he was surprised by the answer: the practitioner told that the most successful sales managers are ones who can recognize "bad" clients and does not waste their time with them. A successful sales manager will instead pass these "bad" clients off to one of their colleagues. This approach allows more time and energy for the "good" clients!

This bit of insight can be helpful to us when we deal with projects. In this paper we hope to show you how to find the good projects, among the bad ones. Because if we can to understand why people are happy with some projects and unhappy with others, then we can focus on the "good" ones, and either not to start the "bad" ones or pass them on to colleagues.
\end{abstract}

Keywords: concept, subjective, emotional, valuation, model, project management

\section{The Topic}

Project success rates are generally low. Why? We are sure, many this article readers will agree, that sometimes project stakeholders are just not happy with the project, once it is delivered. We are assuming that there is some truth to this statement.

But that leads to ask the question: What is causing this low rate of success? We wanted to research the cause of this problem and to design a model that would help to understand why people are happy with some projects and unhappy with others.

In our research we have used a number of theories and mathematical formulas, most of them are explained in our previous work [1]. This paper continues the development and implementation of Subjective Emotional Aspect of Valuation (SEAV).

This paper will take you through a quick overview of the background theories we used, then into our developed model itself. We also will show you some visual representations of the model and will end with conclusions and future directions.

\section{The Traditional Planning}

Traditionally, project planning is the trade-off between the available resources and desired outcomes. If you look at the chart on Fig. 1, the optimal area for a project would lay somewhere in the light field of the chart. The light field contains points with investment level allowable for the project. In the same time the

\footnotetext{
* Corresponding author
} 
light field is above the line where gains and investments level are equal. So, in those points the gains, planned from the project, excess accordant investment level.

In planning a project, a project planner usually attempts to find the optimal area in which is possible to get the most out-come value for the resources spent for the project. In most cases project planners tend to place the project's parameters into most evident point: the right upper corner of the green area. This trend is often referred to as "the biggest bang for the buck" and so called "The Big Bang Point" you could see on upper side of the Fig. 1. As we will see later, this approach is less than ideal. In reality, it is not so clear how to locate the optimal point, as the traditional planning ignores subjective factors usually. We have taken this traditional approach to project planning, and tried to extend and to improve it with our research.

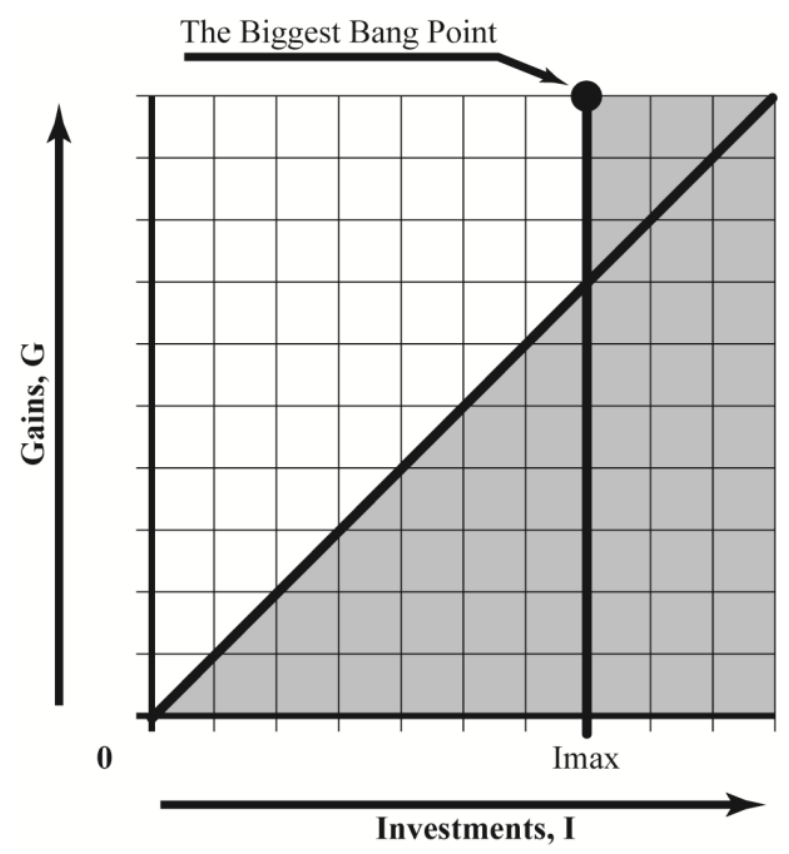

Figure 1. Traditional Planning Approach.

\section{Assumptions}

This research is based on two assumptions. The first assumption is: people often know how they would evaluate in terms of "like" or "dislike". This assumption is developed on the basis of acknowledgement that our behavior is based on evaluations of prospects [2] and the role of emotions in the evaluation process [3]. It is the reason why the Kahneman's and Tversky's observation "we know how we would behave" follows our statement: "we know how we would evaluate". The simplified flowchart summarizing the stages of decision making according to Prospect Theory is shown on Fig. 2.

The second assumption of this research relates to the first one and it is: people's evaluation of the project in terms of "like" or "dislike" is mainly based on the subjective evaluation of the following set of parameters: the efforts they spend to operate these project and gains they get from this operation. 


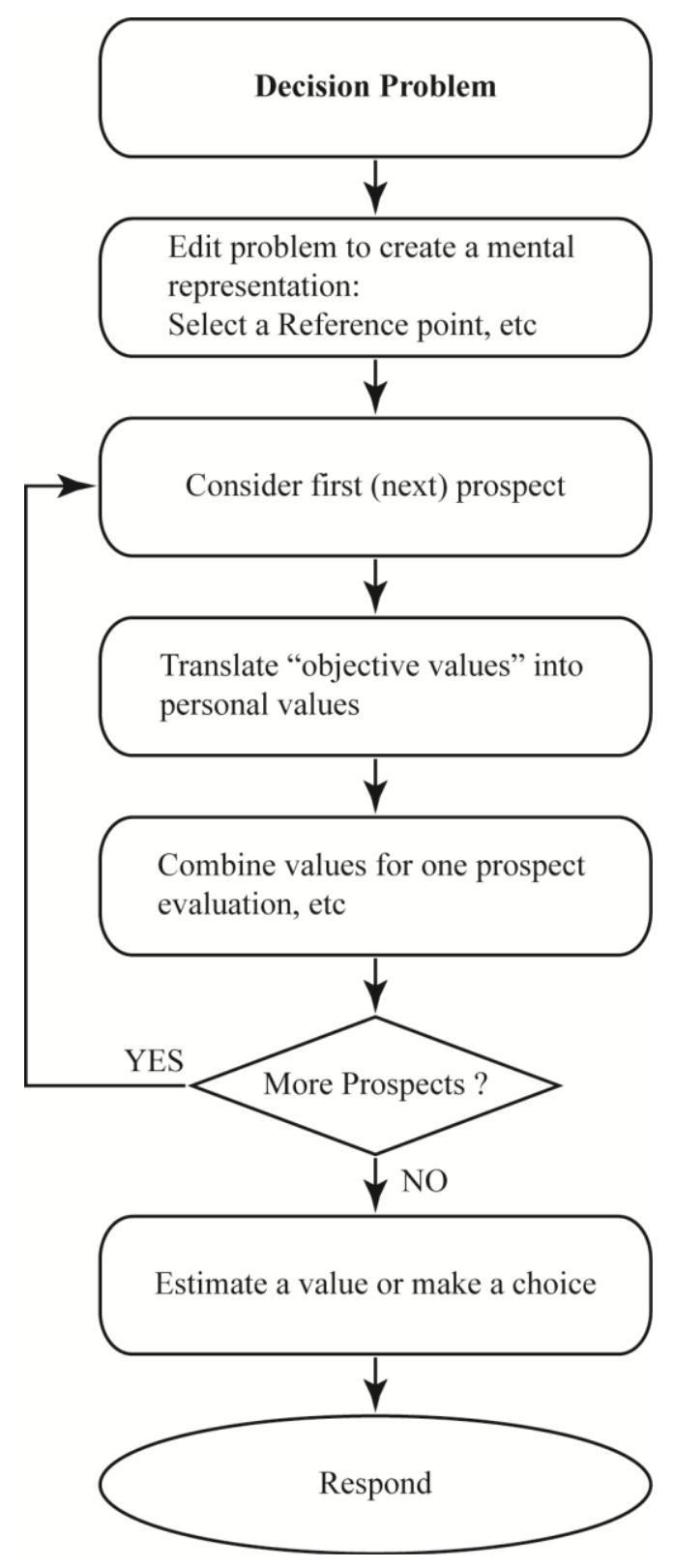

Figure 2. Simplified flowchart summarizing the stages of decision making according to Prospect Theory.

\section{The role of Emotions in the Evaluation Process}

In general, the evaluation process consists of two parts: emotional response and cognitive evaluation. Emotions are the most unpredictable and non-measurable part of our brain activities. Modern neuroscientists acknowledged the reason why emotions are so mysterious: they are based in our subconsciousness [3].

Emotions occur before the cognitive part of the evaluation process and provide "quick and dirty" frame for our response. Even more, the emotions are the factor which mostly determines the remaining alternatives in the choice set for the cognitive part of the evaluation process. Hastie and Dawes [3] have 
the follow ing to say about this: "We would still assign a major role to anticipated emotional responses in the evaluation of the value or utility."

Every of us have personal experience of being some project stakeholder. The projects range could be from family to government or munic ipality activities. Probably, people couldn't remember those details and aims of these projects, but could remember the emotions connected with them - like or dislike.

In case the project is emotionally acceptable for us, for cognitive evaluation we use the so-called positive template. The positive template means that we mainly tend to evaluate project's positive aspects and pay little attention to some noticeable inconveniences and shortcomings. Even more, we are ready to advocate the project team for those inconveniences and shortcomings.

Otherwise, if the project is emotionally unacceptable for us, for cognitive evaluation we use the so-called negative template. The negative template means that we tend to evaluate project's negative aspects mainly and pay little attention to noticeable benefits and necessity of this project. In this case the project team could do the best is possible, but people will sabotage this project without any explainable reason. They probably have only one, but ma in reason to do so: "I dislike it. That's all!" On demand anybody could find thousands of negative reasons, but if he or she were honest, all those reasons would be derived from this main one. And nobody could persuade them to change the ir attitude. But let's be honest again, usually there is not a huge difference between the first case and the second one. And more, very often the second case is objectively better and more necessary.

As explained before, emotions are a very powerful instrument. But before using this instrument, you have to clearly understand how it works in order to use it in the right way. Otherwise the emotions you arouse in the crowd take you down from earth's surface.

\section{Research Area}

The Unified Theory of Acceptance and Use of Technology (UTAUT) is a technology acceptance model formulated in [4]. This theory operates with four core determinants of intention and use, two direct determinants of use-related behavior, and four moderators of key relationships. Like other theories in this area, the UTAUT does not take into account the Prospect Theory Reference point acknowledgement.

Although the UTAUT does not provide an appropriate tool for the SEAV evaluation, it is used as an underpinning for the authors' proposed modified UTAUT model shown on Fig. 3. We generalized the list of core determinants and moderators of key relationships as it is out of scope of our current research. On Fig. 3 you could see our assumption that SEAV acts as one of core determinants of Use Behavior. We also assume that SEAV, in its turn, is a combined parameter, which depends upon the combination of the accordant variables values.

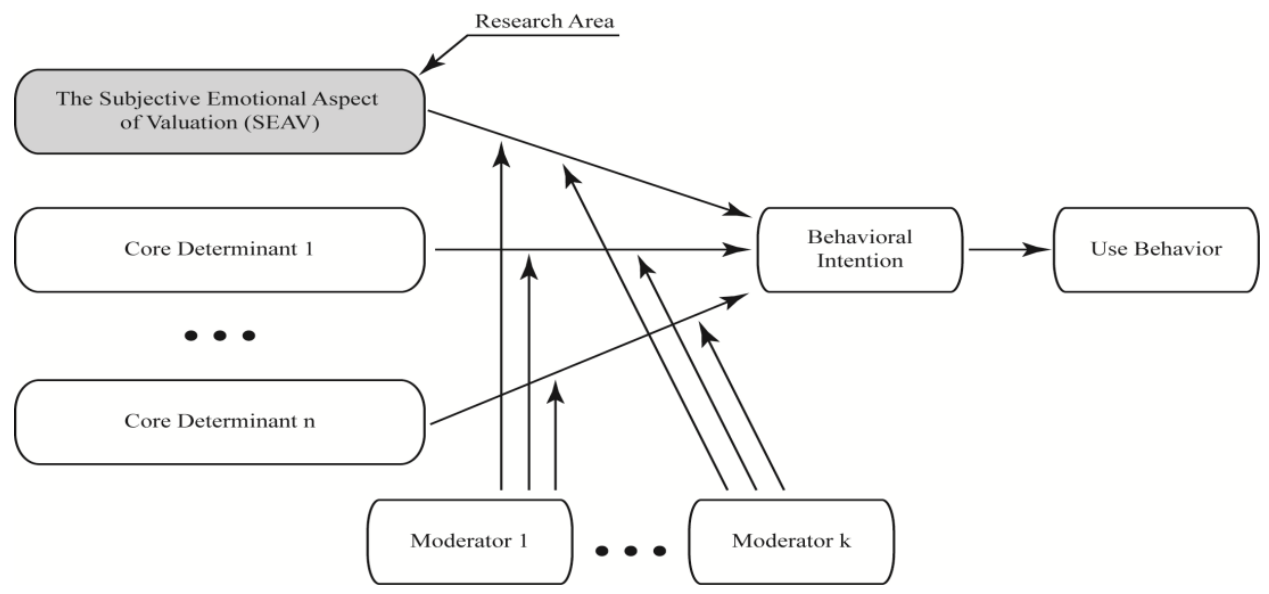

Figure 3. Modified UTAUT Model. 
Let's look on the Research Area in more detail on Fig. 4. The premise is that the emotional response of the project depends on the following parameters' mutual combination:

- Gains Expectancy.

- Effort Expectancy.

- The Reference Point.

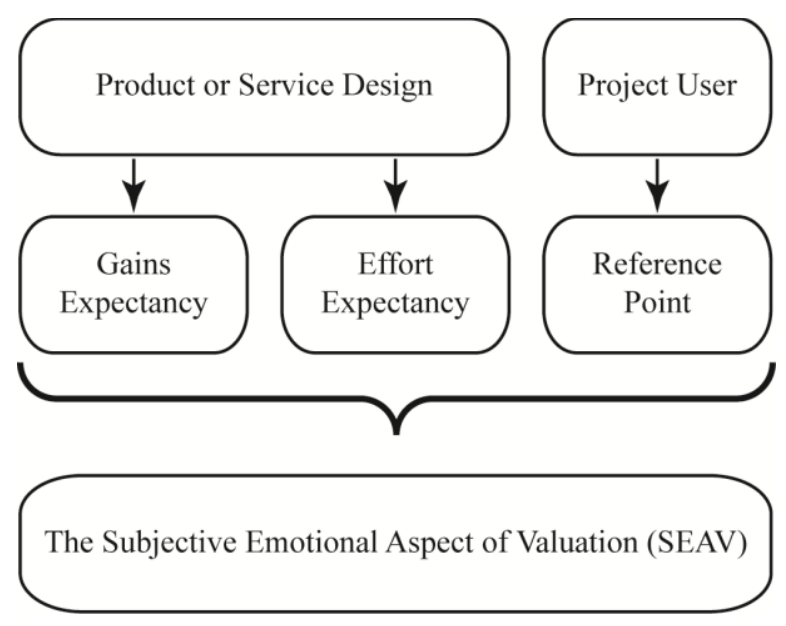

Figure 4. Research Area.

In order to get an appropriate Emotional Evaluation of the project there are some possibilities:

- If stakeholders' Reference Point is given and non-changeable, we should make accordant changes in product or service design before we start the project.

- If the product or service design is given and non-changeable, we should make accordant changes of the stakeholders' Reference Point before we start the project.

We also could change product or service design and the stakeholders' Reference Point simultaneously and in well-coordinated manner.

This means that we should optimize, if it is necessary, the product or service design and Reference Point parameters' combination before we start the project. It is critical to do this in the very early stage of project planning in order to determine the emotional acceptance of the project's deliverables.

We will try to identify relationships between Gains Expectancy, Effort Expectancy, the Reference Point and SEAV in next chapters. 


\section{Equilibrium Lines}

In a 2-dimensional space of normalized efforts and gains we can now start to represent elements of the Emotional Evaluation of the project. This space is represented on Fig. 5.

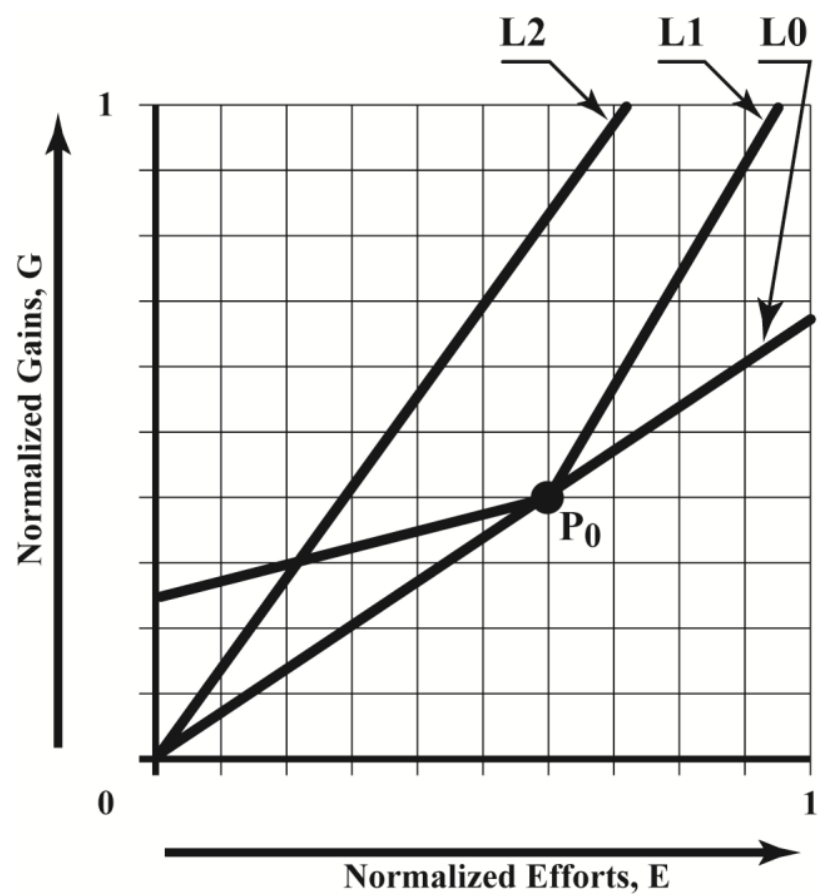

Figure 5. Equilibrium Lines.

The point P0 on Fig. 5 is the project stakeholders' Reference Point before the project starts. The line L0 is the Initial Objective Equilibrium line. It represents the situation before the project starts. It is assumed that until a change in the environment, the proportion between effort stakeholders spent and gains they got is the same as in Reference Point.

The line L1 is the Psychological Equilibrium line. It consists of points that project stakeholders psychologically evaluate as the same as the Reference Point.

The algorithm of Objective Equilibrium line and Psychological Equilibrium line calculations is described in [1].

And finally, line L2 represents the proportion between efforts stakeholders spent and gains they got after the investments are made and project is realized; line L2 is Project Objective Equilibrium line. 


\section{Desirability Lines}

Borrowing from Harrington's desirability theory [5] we can define the relationship between effort and gains into zones. In this research we took into account four parameters. Those parameters are gain and effort measures of the Reference Point and gain and effort evaluation to operate expected project outcome. The result of really extensive calculations, explained in details in [1], you could see on Fig. 6.

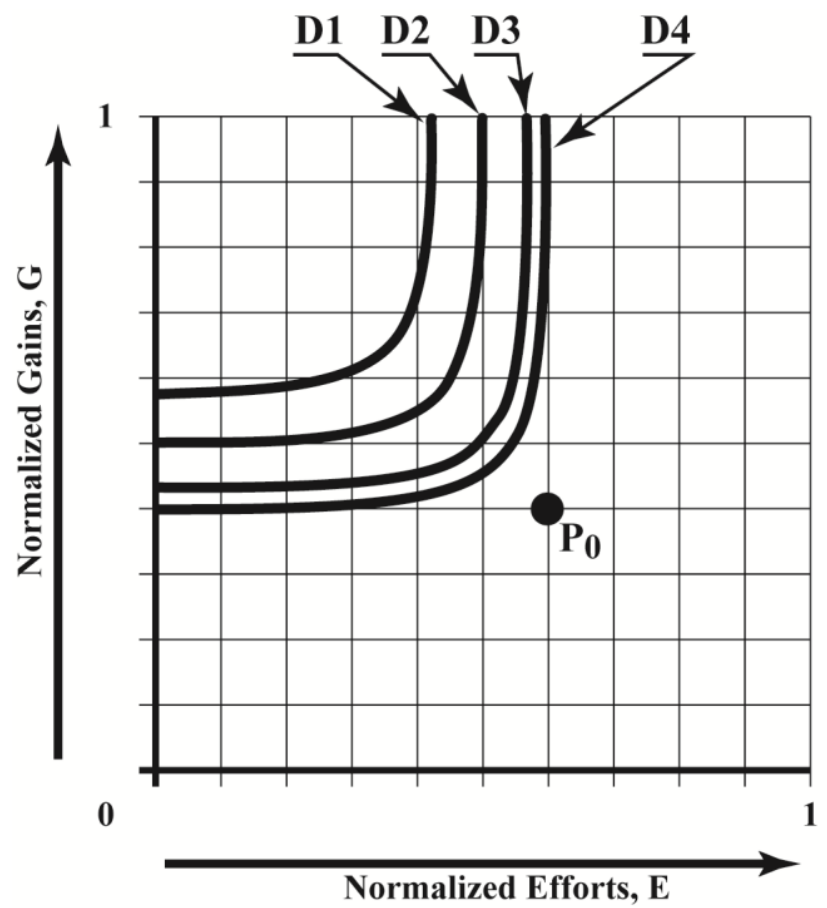

Figure 6. Disequilibrium Lines.

The line D4 and the area below this line is the area of project parameters those are not acceptable for project stakeholders. The line D3 consists of points with acceptable, but poor emotional acceptance. In its turn, the area between the line D3 and line D4 represents "not so good" project's parameters.

The line D4 and the area below this line is the area of project parameters those are not acceptable for project stakeholders. The line D3 consists of points with acceptable, but poor emotional acceptance. In its turn, the area between the line D3 and line D4 represents "not so good" project's parameters.

The line D2 represents points with the best commercial quality. So, the area between D2 and D3 lines is a dream area for a modest project manager. It is "not so bad" project's parameters' area.

The line D1 represents points of a project's parameters that project stakeholders evaluate as excellent.

The area between the line D1 and line D2 the research authors consider as the target area for project planning. Of course, this area consists of some subareas that differ in practice. We will discuss this topic later.

And finally, we assume the area above the line D1 represents projects that will be probably evaluated as overspending, as investments spent to reach those parameters will not increase project stakeholders' emotional acceptance of the project.

It is very important, that the calculation's algorithm of the SEAV, instead other theories in this area, includes measures of both the Reference Point and project outcomes. 


\section{Optimal Planning}

As promised, let's discuss about the optimal area for project planning and some it subareas in more details. The area below line D4 on Fig. 7 represents "not so good" project's parameters. We excluded them from further examination.

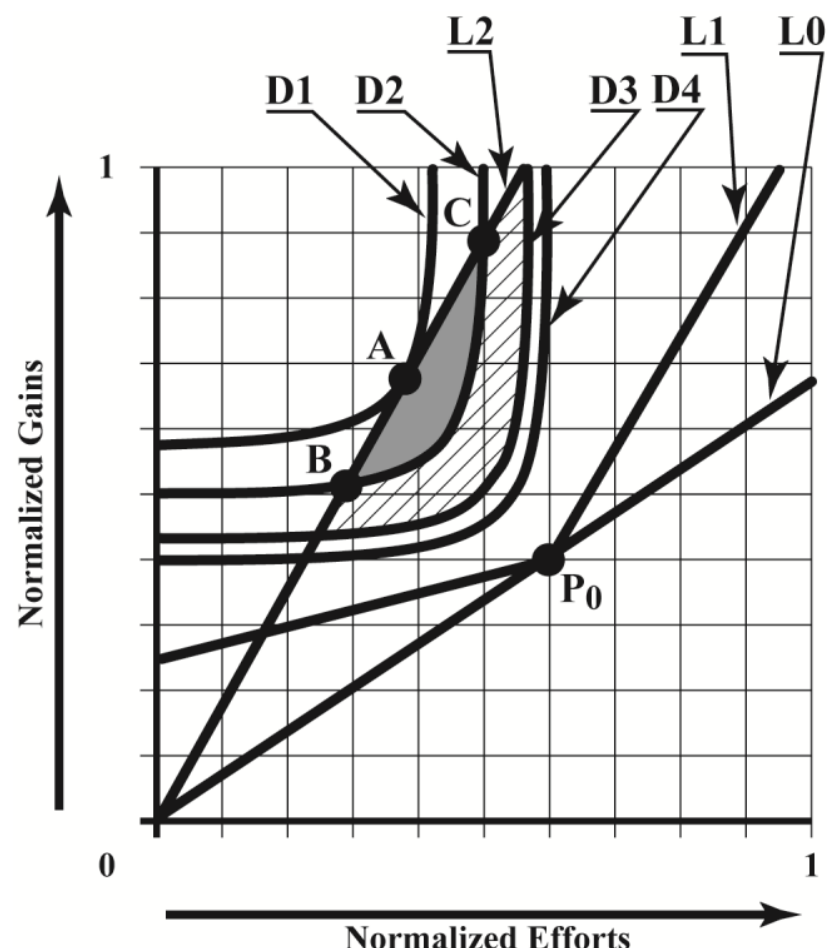

Figure 7. Optimal Planning.

The point A is most exclusive point. It is a point where line L2, the Project Objective Equilibrium line, touches the project's excellent parameters line, the line D1. Point A has excellent emotional evaluation with minimum possible proportion between gains, that project stakeholders got, and efforts they spent to operate.

We assume that in case of proper project design bigger investments in project will lead to bigger proportion between gains, that project stakeholders got, and efforts they spent to operate. This proportion directly correlates with the size of angle between Normalized Efforts axe and line L2, because the proportion between gains, that project stakeholders got, and efforts they spent to operate is the tangent of this angle.

So the point $\mathrm{A}$ is the point with excellent emotional evaluation which is reached with minimum possible investments' level. This set of very important properties justified us to evaluate and to name the point A as the Optimal Project Point.

In its turn, the Project Objective Equilibrium line, which crosses the Optimal Project Point, will be named as the Optimal Investment Line and accordant investment level will be named as the Optimal Investment Level.

It is evidently, that area above the Optimal Investment Line represents parameters of projects with higher level of investments. This area is thankless for project planning as in any case it will be evaluated by project stakeholders as overspending definitely.

So, after dissection we did above, there are left only two areas, those have acceptable emotional valuation and in the same time are evaluated by project stakeholders as adequate spending: the shaded area 
represented "not so bad" projects and the gray area, represents projects with emotional evaluation between excellent and best commercial quality.

There are many interesting things to say about those areas. For an example, you see, that the minimum difference between excellent and best commercial quality is about $10 \%$ from efforts maximum value. The same minimum difference is also between best commercial quality and "not so good" projects.

The other interesting thing is practical consequences from the difference between point B and C. Both points are intersection points between Optimal Investment Line and the line represented projects evaluated as the best commercial qua lity.

Project with point's B parameters has nominal emotional evaluation as the best commercial quality, but very easy becomes "not so good" project, if stakeholders will undervaluate gains they got from it. From other side, there is noticeable damper zone to keep positive emotional evaluation if stakeholders overvaluate their efforts.

The point $\mathrm{C}$ has the opposite characteristics. Project with point's $\mathrm{C}$ parameters also has nominal emotional evaluation as the best commercial quality, but very easily becomes a "not so good" project, if stakeholders will overvaluate the ir efforts. From other side, there is much bigger damper zone to keep positive emotional evaluation if project stakeholders undervaluate gains they got from it.

In light of above mentioned, the point A, the Optimal Project Point, has most balanced characteristics. It has noticeable damper zone to keep positive emotional evaluation if stakeholders become overvaluate their efforts or undervaluate gains they got.

\subsection{Model}

On Fig. 8 you could see our concept presented in 3-dimensional space. Those dimensions are normalized Investments, Gains and Efforts. The cube consists of points, represented projects with all possible combinations of above mentioned parameters.

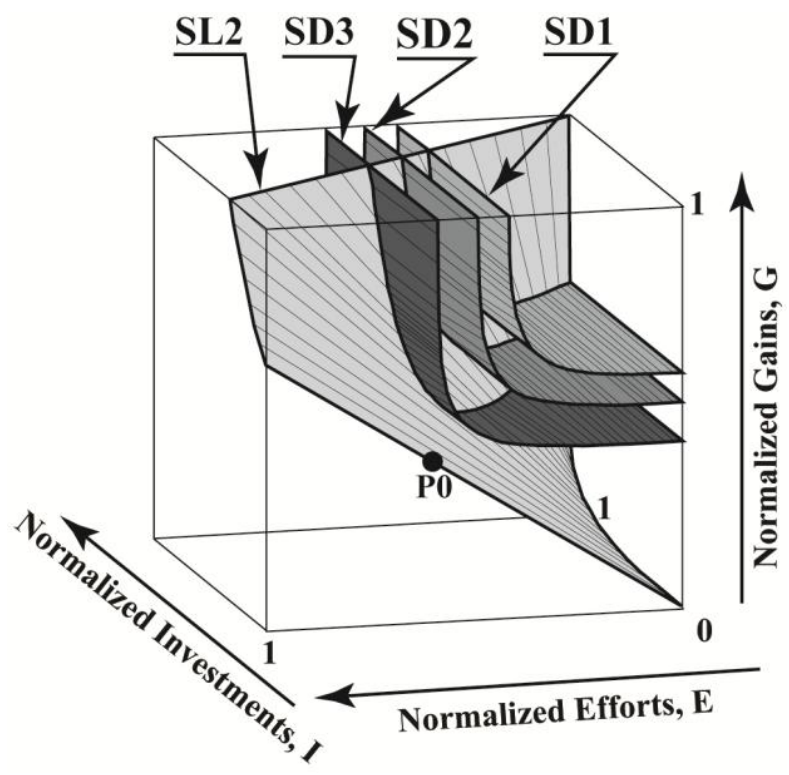

Figure 8. Traditiona1 Planning Approach. 
The 3-dimensional space of projects' parameters elements are as following:

- The point P0 is the Reference Point.

- The surface SL2 contains Project Objective Equilibrium lines for accordant level of investments.

- The surface SD3 contains points with acceptable, but poor emotional acceptance.

- The surface SD2 contains points with best commercial quality emotional acceptance.

- The surface SD1 contains points with excellent emotional acceptance.

There are some interesting consequences from the 3D model:

- The surface SL2 represents points with most effective usage of accordant level of investments.

- Projects planned with parameters above the surface SL2 are quarantined to fall, as the allowed level of investments is less than necessary to achieve goals planned.

- In its turn, at the area below the surface SL2 investments are not so effectively used. As the project point is more below from the red surface, it is less effective.

- The surface SL2 is cut by surfaces SD1, SD2 and SD3 to 4 areas; those could be investigated in similar manner as we did with 2-dimensional model on Fig. 7.

\section{Conclusions}

The main conclusions of presented concept are as follows:

- The 3-dimensional space normalized Investments, Gains and Efforts contains indefinite amount on points represented projects with different sets of those parameters, but only one of those points could be evaluated as the Optimal Project Point. It is presented as a point A on the Fig. 7; the position of this point on Fig. 8 could be identified using the same approach. The only small area of parameters near the Optimal Project Point will get a positive emotional acceptance for the project from project stakeholders. A project with parameters outside this area is doomed to failure or to obstruction from project stakeholders regardless of the project team qualifications and efforts they spent.

- The position of the Optimal Project Point in the 3-dimensional space of normalized Investments, Gains and Efforts could be different for the same projects in different initial conditions, and it depends from the Reference Point coordinates.

- It is very important to recognize the Optimal Project Point coordinates in very early project planning stage in order to increase projects' success rate.

- The current low projects success rate is a consequence of traditional project planning approach, which ignores emotional evaluation of the project.

And the last comment: details necessary for concept details tracking and understanding you can find in [1]. 


\section{Future Work}

We plan to implement the SEAV conceptual model in easy to use form: SEAV Calculator software.

We are looking for:

- Grants.

- Cooperation.

- Publications.

- Comments, suggestions and proposals.

We modestly consider the proposed concept is a breakthrough in Project Management discipline. There are huge possibilities to develop this concept to a level enough to provide valuable outcomes to Project Management practitioners. So, we look for response and cooperation from Project Management society. Your support, comments, suggestions and involvement are highly welcome.

\section{REFERENCES}

[1] G. Mote and J. Bowen A, "Conceptual Model of the Emotional Valuation of a Project," in Conf. Rec. 2010 PMI Research and Education Conference, Washington, DC. [Online]. Available: http://marketplace.pmi.org/Pages/ProductDetail.aspx?GMProduct=00101244101

[2] D. Kahneman and A. Tversky, (1979). Prospect Theory: An Analysis of Decision under Risk. JSTOR. [Online]. Available: http://links.jstor.org/sici?sici=00129682\% $28197903 \% 2947 \% 3 \mathrm{~A} 2 \% 3 \mathrm{C} 263 \% 3 \mathrm{APTAAOD} \% 3 \mathrm{E} 2.0 . \mathrm{CO} \% 3 \mathrm{~B} 2-3$

[3] R.Hastie and R.M. Dawes, Rational Choice in an Uncertain World: The Psychology of Judgment and Decision Making. Thousand Oaks, CA, USA: Sage Publications. 2001.

[4] V. Venkatesh, M. G. Morris, G. B. Davis and D. F. Davis, (2003). User acceptance of information technology: toward a unified view. Collaborative Software Development Laboratory. [Online]. Available: http://csdl. ics.hawaii.edu/techreports/05-06/doc/Venkatesh2003.pdf

[5] E. C., Jr., Harrington, (1965). The Desirability Function. American Society for Quality. [Online]. Available: $\underline{\text { http://www.asq.org/qic/display-item/index.html?item }=4860}$ 